Dhun H. Sethna MD, Norman J. Starr MD, Fawzy G. Estafanous MD

\title{
Cardiovascular effects of non-depolarizing neuromuscular blockers in patients with aortic valve disease
}

To compare haemodynamic responses associated with equipotent doses of neuromuscular blockers and high-dose fentanyt $\left(50 \mu \mathrm{g} \cdot \mathrm{kg}^{-1}\right), 40$ patiems with aortic valve stenosis (AS) and 20 patients with aortic insufficiency (AV) were randomized to four sudy groups to receive the following: (1) pancuronium $0.12 \mathrm{mg} \cdot \mathrm{kg}^{-1}$, (2) verturonium $0.12 \mathrm{mg}-\mathrm{kg}^{-1}$, (3) atracurium $0.4 \mathrm{mg} \cdot \mathrm{kg}^{-1}$, or (4) pancuronium-metocurine mixture $(0.4 \mathrm{mg}+$ $1.6 \mathrm{mg} / \mathrm{m}$ ) $): 1 \mathrm{ml} / \mathrm{lo} \mathrm{kg}$ ). Neuromuscular blockers were injected at the same time with the fentanyl; haemadynamics were recorded with the patients awake (baseline), at two minutes post-induction, and at wo and five minutes after insubation.

In patiends with $A S$, pancuronium increased heart rate more than vecuronium or atracurium; heart rates were also higher with the pancuronium-metocurine mixture than with vecuronium. Although there were no ECG signs of ischaemia, one patient given parcuronium developed severe hypotension associated with tachycardia. Reductions in SVR after atracurium allowed small but significant $(p<0.01)$ decreases in MAP which were well tolerated; one patient, however, did develop severe hypotension. Intabation resulted in significant $(p<0.0 I)$ increases in MAP in the pancuronium-metocurine mixture group. Vecuronium permitted the most stable overall haemodynamic course at all measurement times.

In contrast, potients with $A I$ showed stable haemodynamics after vecuronium, pancuronium and the pancuronium-metocurine mixtuse; one patient became tachycardic following vecuronium. Atracurium caused unexplained elevations in diastolic and mean arterial pressures which were significant when compared to vecuronium $(p<0.0 I)$. These resulted in increases in PCWP; mean PA pressures and CVP were also increased. These effects of arracurium in patients with Al need further evaluation.

\section{Key words}

NEUROMUSCULAR RELAXANTS: pancuronium, vecuronium, atracurium, metocurine; ANAESTHETICS INTRAVENOUS: fentanyl; ANAESTHESIA: cardioyascular.

From The Cleveland Clinic Foundation, Department of Cardiothoracic Anesthesia, Cleveland, Ohio.

Address correspondence to: Dr. Norman J. Starr, Deparment of Cardiothoracic Anesthesia, 9500 Euclid Avenue, Cleveland, Ohio 44106.
Cardiovascular effects of non-depolarizing neuromuscular blocking drugs related to histamine release or to effects on the autonomic nervous system ${ }^{1,2}$ may be especially important in the anaesthetic management of patients with aortic stenosis or aortic insufficiency. Hypotension and tachycardia are poorly tolerated in aortic stenosis, with early development of myocardial ischaemia, while elevations in blood pressure can increase the regurgitant fraction in aortic insufficiency, Recently, combinations of neuromuscular blockers have been examined permitting use of lower doses with reduction of dose-dependent cardiovascular effects. ${ }^{3}$ The two new competitive blocking agents, atracurium and vecuronjum, have been shown to provide adequate muscular relaxation without significant haemodynamic changes in healthy subjects and patients with coronary artery disease. ${ }^{4}$ The present study was undertaken to compare the cardiovascular responses associated with vecuronium, atracurium and a pancuroniummetocurine mixture with those of pancuronium, when used with high-dose fentanyl anesthesia in patients with aortic valvular stcnosis or aortic insufficiency.

\section{Methods}

Forty patients with aortic stenosis and 20 patients with aortic insufficiency were studied with informed consent, according to a protocal approved by the Human Subjects Committee. All patients had significant aortic valve disease and were scheduled for elective aortic valve replacement surgery. Thirtecn paticnts with aortic stenosis and five patients with aortic insufficiency had associated coronary artery disease ( $>75$ per cent diameter narrowing in at least one coronary artery). Twenty-four patients with aortic stenosis, and ten with aortic insufficiency were in sinus thythm; the remaining patients had atrial fibrillation on the baseline ECG. Excluded from the study were patients with significant liver and kidney disease (defined as serum bilirubin and creatinine levels greater than twice normal), other valvular heart disease and those who were clinically unstable (NYHA Class IV). Digitalis, beta adrenergic blocker and calcium channel blocker therapies were continued up to the morning of surgery. 
TABLE I Preoperative data. Mean \pm SD or number of patients

\begin{tabular}{|c|c|c|c|c|c|c|c|c|}
\hline & \multicolumn{2}{|c|}{ Atracurium } & \multicolumn{2}{|c|}{ Vecturonium } & \multicolumn{2}{|c|}{ Pancuronium } & \multicolumn{2}{|c|}{$\begin{array}{l}\text { Pancuronium- } \\
\text { metocurine mixture }\end{array}$} \\
\hline & $A S$ & $A R$ & AS & $A R$ & AS & $A R$ & $A S$ & $A R$ \\
\hline Age (yr) & $61 \pm 7$ & $49 \pm 16$ & $58 \pm 7$ & $53 \pm 14$ & $62 \pm 5$ & $54 \pm 14$ & $55 \pm 10$ & $58 \pm 5$ \\
\hline Male & 5 & 5 & 6 & 4 & 9 & 4 & 8 & 4 \\
\hline $\begin{array}{l}\text { Weight }(\mathrm{kg}) \\
\text { Ao gradient }\end{array}$ & $\begin{array}{l}78 \pm 14 \\
78 \pm 23\end{array}$ & $69 \pm 34$ & $\begin{array}{l}77 \pm 14 \\
77 \pm 40\end{array}$ & $78 \pm 14$ & $\begin{array}{l}75 \pm 27 \\
67 \pm 31\end{array}$ & $86 \pm 6$ & $\begin{array}{l}79 \pm 10 \\
80 \pm 19\end{array}$ & $87 \pm 24$ \\
\hline CAD & 4 & 1 & 2 & 2 & 4 & 0 & 3 & 2 \\
\hline Digitalis & 2 & 2 & 1 & 3 & 3 & 3 & 2 & 4 \\
\hline Beta-blocker & 2 & 1 & 1 & 0 & 4 & 1 & 1 & 2 \\
\hline Ca-antagonist & 1 & 0 & 2 & 1 & 2 & 1 & 0 & 1 \\
\hline Sinus rhythm & 5 & 2 & 5 & 4 & 6 & 1 & 8 & 3 \\
\hline
\end{tabular}

$n=10$ for $A S ; n=5$ for $A R ; A 0=$ aortic valve; $A S=$ aortic stenosis; $A R=$ aortic rc gurgitation; $C A D=$ associated coronary artery disease.

Patients were premedicated with morphine $0.1 \mathrm{mg} \cdot \mathrm{kg}^{-1}$ IM and scopolamine $0.4 \mathrm{mg} \mathrm{IM}$. In each patient, a 20-gauge cannula was inserted in a radial artery, and a triple lumen flow-directed pulmonary artery catheter was introduced into the pulmonary artery. Patients were randomly allocated to one of four study groups as follows: (1) pancuronium $0.12 \mathrm{mg} \cdot \mathrm{kg}^{-1} \mathrm{IV}$; (2) vecuronium $0.12 \mathrm{mg} \cdot \mathrm{kg}^{-1} \mathrm{IV} ;$ (3) atracurium $0.4 \mathrm{mg} \cdot \mathrm{kg}^{-1} \mathrm{IV}$; (4) pancuronium-metocurine mixture $\left(0.4 \mathrm{mg}+1.6 \mathrm{mg} \cdot \mathrm{kg}^{-1}\right)$ : $\mathrm{I} \mathrm{ml} / 10 \mathrm{~kg} \mathrm{IV}$. Anaesthesia was induced with fentanyl 50 $\mu \mathrm{g} \cdot \mathrm{kg}^{-1}$ during administration of 100 per cent $\mathrm{O}_{2}$. Twenty per cent of the calculated neuromuscular blocker dose was given initially to avoid fentanyl rigidity; immediately thereafter, the remaining drug and fentanyl were given by simultaneous injection. The mean duration of fentanyl and remainder of neuromuscular blocker injection was three minutes. All patients were intubated at the first attempt, without difficulty, after the postinduction measurements were completed.

Baseline (awake) haemodynamic measurements were made when heart rate and blood pressure had stabilized after insertion of intravascular catheters (about five minutes). Measurements at enc' expiration were repeated at two minutes after induction, and at two and five minutes following intubation. Pressures were measured with transducers zeroed to the mid-axillary line. Systemic, pulmonary arterial and central venous pressures, electrocardiogram lead $V_{5}$ and the patient's clinical condition was monitored continually, and electrocardiogram limb leads intermittently.

Haemodynamic measurements were obtained using a computer programmed to record pressures and heart rate at specific times. Cardiac outputs were measured by thermodilution and expressed as the mean from two wellformed curves agreeing within ten per cent. Haemodynamic indices were calculated from pressure and cardiac output measurements according to standard formulae.
Myocardial ischaemia on the ECG was defined as $>1 \mathrm{~mm}$ ST segment depression occuring in at least three consecutive heartbeats when measured at $80 \mathrm{msec}$ after the J point, using the PR interval of each complex as baseline. The ECG was standardized as $\mathbf{I ~} \mathrm{mV}=10 \mathrm{~mm}$. Patients were specifically treated if mean arterial pressure fell below 60 $\mathrm{mmHg}$ ("severe hypotension"), or heart rates exceeded baseline values by 30 per cent. No other drugs or fluids were given during the study.

Ventilation was assisted manually using 100 per cent oxygen and a mask and, following intubation, controlled with 100 per cent oxygen using the non-rebreathing circuit of an Engstrom ventilator. Respiratory rate and tidal volume were adjusted to maintain $\mathrm{PaCO}_{2}$ about 40 $\mathrm{mmHg}$. Statistical evaluation was by analysis of variance. Differences betwcen the four neuromuscular blocker groups at the same measurement time were examined by a one-way ANOVA followed by $t$ tests when $F$ was significant. For differences in haemodynamic parameters between sequential measurements and baseline values within the same drug group, a one-way repeated measures ANOVA was performed, followed by paired $t$ tests when $F$ was significant. The significance level used for analysis of variance was the traditional 0.05 . Since multiple $t$ tests were performed, a more conservative nominal significant level of 0.01 was used for these pairwise comparisons to adjust in part for the problem of simultaneous statistical inference. $^{s, 6}$

\section{Results}

Patients in the four study groups were comparable for age, sex, body weight, aortic valve gradient (in patients with aortic stenosis), presence of coronary artery disease, and preoperative digitalis, beta adrenergic and calcium channel blocker therapy (Table I). Also, there were no significant differences in baseline haemodynamics be- 

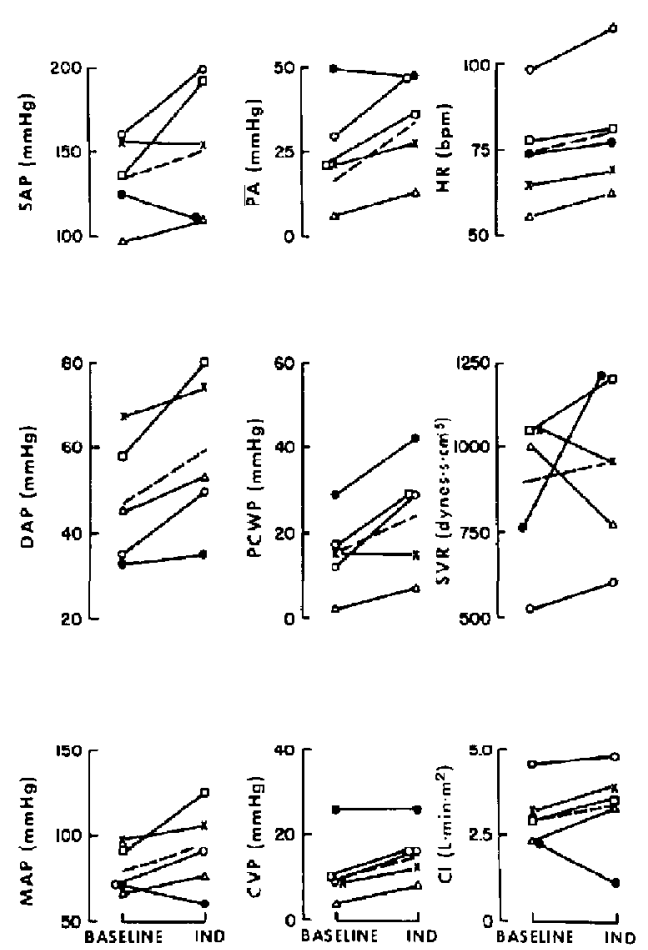

FIGURE I Induction with fentanyl-atracurium in five patients with chronic aortic regurgitation. Individual patient responses are shown; mean changes in haemodynamic parameters are indicated. (-- ) . SAP = systolic arterial pressure; DAP = diastolic arterial pressure; $\mathrm{PA}=$ mean pulmonary artery pressure; other abbreviations as in Table II.

tween groups in patients with aortic stenosis (Table II) or aortic regurgitation (Figures 1 and 2).

\section{Aortic stenosis}

Cardiovascular responses to induction and intubation are summarized in Table II. After fentanyl-pancuronium, heart rate increased by 24 per cent which was statistically insignificant compared with a 17 per cent change in the pancuronium-metocurine group. One patient developed tachycardia and severe hypotension after pancuronium and required vasopressor therapy. Intubation resulted in further increases in mean heart rates which were higher than baseline values and, in the pancuronium-metocurine group, were accompanied by significant elevations ( $\mathrm{p}<$ $0.01)$ in mean arterial pressure. Patients given fentanylatracurium showed, on average, an $11 \mathrm{mmHg}$ fall in mean arterial pressure after induction $(p<0.01)$, with a return to baseline values following intubation. One patient de-
TABLE II Haemodynamic meuurements (Mean $\pm S E$ ) awake, after induction and after intubation in the four musclc relaxant groups in patients with aortic stenosis. All patients were induced with high-dose fentanyl

\begin{tabular}{lcccr}
\hline & $\begin{array}{c}\text { Baseline } \\
\text { (Awake) }\end{array}$ & $\begin{array}{l}\text { Induction } \\
+2 \text { min }\end{array}$ & $\begin{array}{l}\text { Inubasion } \\
+2 \text { mirt }\end{array}$ & $\begin{array}{l}\text { Iasubation } \\
+5 \text { min }\end{array}$ \\
\hline$H R$ & & & & \\
Y & $73 \pm 5$ & $73 \pm 4$ & $72 \pm 5$ & $66 \pm 6$ \\
P & $76 \pm 9$ & $94 \pm 10$ & $96 \pm 10$ & $87 \pm 8$ \\
A & $78 \pm 5$ & $72 \pm 7$ & $75 \pm 7$ & $70 \pm 6$ \\
PM & $77 \pm 4$ & $90 \pm 4$ & $94 \pm 5$ & $86 \pm 5$
\end{tabular}

\begin{tabular}{|c|c|c|c|c|}
\hline v & $93 \pm 7$ & $97 \pm 6$ & $104 \pm 6$ & $96 \pm 5$ \\
\hline $\mathbf{P}$ & $92 \pm 5$ & $93 \pm 5$ & $97 \pm 6$ & $94 \pm 6$ \\
\hline A & $90 \pm 2$ & $79 \pm 5^{4}$ & $90 \pm 4$ & $87 \pm 4$ \\
\hline $\mathbf{P M}$ & $95 \pm 5$ & $94 \pm 5$ & $107 \pm 5^{*}$ & $101 \pm 5$ \\
\hline \multicolumn{5}{|c|}{ PCWP } \\
\hline$Y$ & $14 \pm 2$ & $17 \pm 4$ & $21 \pm 5$ & $16 \pm 2$ \\
\hline $\mathbf{p}$ & $16 \pm 3$ & $16 \pm 4$ & $15 \pm 3$ & $9 \pm 1$ \\
\hline A & $18 \pm 4$ & $15 \pm 2$ & $17 \pm 3$ & $17 \pm 4$ \\
\hline $\mathrm{M}$ & $13 \pm 2$ & $16 \pm 3$ & $18 \pm 3$ & $17 \pm 3$ \\
\hline \multicolumn{5}{|l|}{ CVP } \\
\hline 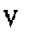 & $6 \pm 1$ & $9 \pm 1$ & $10 \pm 1$ & $10 \pm 1$ \\
\hline P & $7 \pm 1$ & $10 \pm 1$ & $9 \pm 1$ & $15=3$ \\
\hline$\Lambda$ & $7 \pm 1$ & $10 \pm 2$ & $10 \pm 1$ & $10=1$ \\
\hline PM & $7 \pm 1$ & $10 \pm 1$ & $10 \pm 1$ & $9 \pm 1$ \\
\hline \multicolumn{5}{|l|}{$\mathrm{Cl}$} \\
\hline $\mathrm{v}$ & $3.0 \pm 0.2$ & $2.8 \pm 0.2$ & $2.9 \pm 0.3$ & $2.9 \pm 0.4$ \\
\hline $\mathbf{p}$ & $3.1 \pm 0.2$ & $3.2 \pm 0.2$ & $3.5 \pm 0.2$ & $3.3 \pm 0.3$ \\
\hline A & $3.1 \pm 0.2$ & $2.9 \pm 0.2$ & $2.9 \pm 0.4$ & $2.8 \pm 0.3$ \\
\hline DY & $3.0 \pm 0.2$ & $3.0 \pm 0.2$ & $3.3 \pm 0.2$ & $3.4 \pm 0.3$ \\
\hline \multicolumn{5}{|l|}{ SVR } \\
\hline $\mathrm{v}$ & $1306 \pm 124$ & $1419 \pm 157$ & $1496 \pm 165$ & $1422=179$ \\
\hline $\mathbf{P}$ & $1137 \pm 79$ & $1076 \pm 68$ & $1066 \pm 72$ & $1081 \pm 78$ \\
\hline 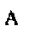 & $1176 \pm 63$ & $1095 \pm 88$ & $1298 \pm 106$ & $1310=108$ \\
\hline $\mathrm{M}$ & $1259 \pm 104$ & $1219 \pm 71$ & $1265 \pm 88$ & $1208=85$ \\
\hline
\end{tabular}

$\mathrm{V}=$ vecunonium; $\Lambda$ = atricurium; $\mathrm{P}=$ pancuronium; $\mathrm{PM}=$ pancuroniummetocurine mixture; HR = heart rate (beats $\left.\cdot \min ^{-1}\right) ; \mathrm{MAP}=$ mean arerial pressure (mmHg); $P C W P=$ pulmonary capillary wedge pressure (mmHg); CVP = central. venous pressure $(\mathrm{mmH}) ; \mathrm{Cl}=$ cardiac index $\left(\mathbf{L} \cdot \mathrm{min}^{-1} \cdot \mathrm{m}^{-\mathbf{2}}\right) ; \mathrm{SVR}=$ systemic vascular nesistance $\left(\mathrm{dyne} \cdot \mathrm{sec}^{\prime} \mathrm{cm}^{-5}\right)$. ${ }^{*} p<0.01$ when compared to baseline for the sume drug.

veloped severe hypotension requiring vasopressor treatment. Vecuronium, in general, permitted the most stable cardiovascular course in patients with aortic stenosis, with no significant haemodynamic changes being observed at any measurement time.

The per cent increases in heart rate over basal values were higher after induction in patients who had received fentanyl-pancuronium than in those who were given fentanyl-vecuronium (24 per cent vs 0 per cent; $p=0.04$ ) or fentanyl-atracurium ( 24 per cent vs -8 per cent; $p=$ 


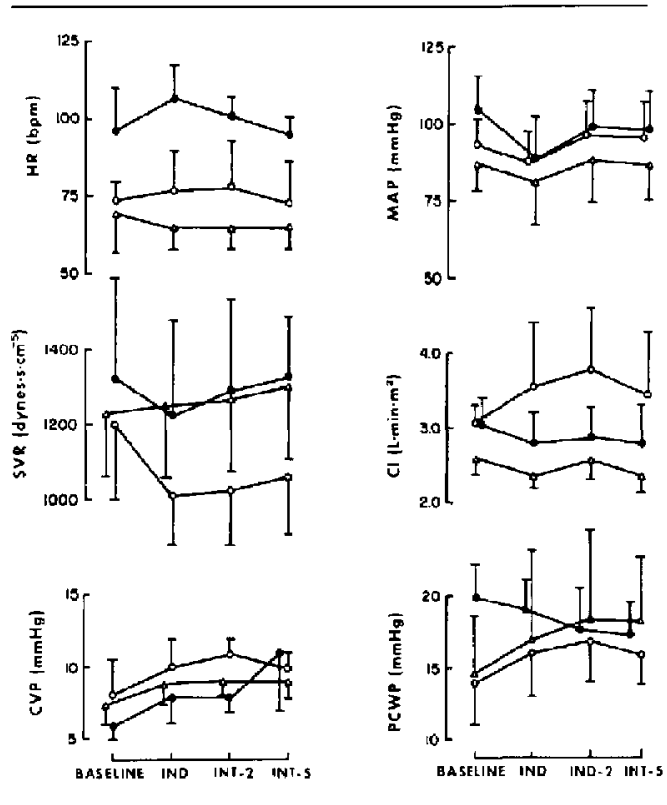

FIGURE 2 Cardiovascilar effects (mean \pm SE) of vecuronium (0.12 $\left.\mathbf{m g} \cdot \mathrm{kg}^{-1}\right)$, pancuronium $\left(0.12 \mathrm{mg} \cdot \mathrm{kg}^{-1}\right)$ and pancuronium-metocurine mixture $(0.4 \mathrm{mg}+1.6 \mathrm{mg} / \mathrm{ml}: 1 \mathrm{ml} / 10 \mathrm{~kg})$ in patients with chronic aortic regurgitation. $\mathrm{O}-\mathrm{O}=$ vecuronium; $-\mathrm{O}=$ pancuronium; $\Delta-\Delta=$ pancuronium-metocurine mixture. Abbreviations as in Table II.

0.02); the difference persisted at 2 minutes after intubation between the fentanyl-pancuronitm and fentanylvecuronium groups ( 26 per cent vs -0.1 per cent). Heart rates also increased more at two minutes after intubation in the pancuronium-metocurine group when compared with those who were given vecuronium ( 22 per cent vs -0.1 per cent).

\section{Aortic insufficiency}

Cardiovascular responses to induction and intubation are summarized in Figures 1 and 2. Significant, unexplained cardiovascular changes occurred in the fentanyl-atracurium group when compared to baseline values. Atracurium was associated with increases in diastolic and mean arterial pressures in four of five patients, along with elevations in left ventricular filling pressures (Figure 1). SVR and cardiac index were unchanged. Mean pulmonary artery pressures also increased resulting in elevations in CVP. These changes were clinically well tolerated. In contrast to patients with aortic stenosis, pancuronium and the pancuronium-metocurine mixture allowed only minimal cardiovascular changes to occur in those with aortic insufficiency (Figure 2). One patient in the fentanylvecuronium group showed a tachycardia after induction, requiring treatment with propranolol; haemodynamics remained stable in the remaining patients in this group.

Comparison between the four neuromuscular blocker groups showed that patients given fentanyl-atracurium had increases in systolic, diastolic and mean arterial pressures with elevations in pulmonary capillary wedge pressures indicating responses that were different ( $p=$ 0.04 ) to those who had reccived fentanyl-pancuronium, in whom systemic pressures fell after induction, with small decreases in left ventricular filling pressures. Similarly, increases in mean arterial pressures in the fentanylatracurium group showed a trend that was different ( $\mathrm{p}=$ $0.04)$ to those who had received fentanyl-vecuronium in whom blood pressures fell minimally. These differences were also clinically well tolerated.

\section{Aortic stenosis vs aortic insufficiency}

Atracurium was the only drug associated with significant circulatory differences between the two groups. Thus, increases in systolic, diastolic and mean arterial pressures occurred in aortic insufficiency patients, whereas those with aortic stenosis showed a fall in systemic pressures on induction of anaesthesia.

Satisfactory muscle relaxation for intubation was present in all patients. Fentanyl rigidity was successfully avoided. Continued electrocardiographic monitoring showed no alterations in cardiac rhythm, ST segments or $T$ waves except in one patient with aortic insufficiency who developed frequent PVC's after induction with fentanylatracurium.

\section{Discussion}

In this study pancuronium, which is a drug commonly used in patients undergoing aortic valve surgery, was compared with atracurium, vecuronium and a pancuroniummetocurine mixture. Doses in excess of $\mathrm{ED}_{95}$ were given to provide satisfactory neuromuscular blockade for endotracheal intubation. The potency of vecuronium is equal to or slightly greater than pancuronium $(1-1.74: 1)$, whereas atracurium is less potent than pancuronium (0.25-0.33:1). ${ }^{4}$ Under narcotic-nitrous oxide anaesthesia, vecuronium has been shown to be as potent as pancuronium in producing 95 per cent twitch depression; ${ }^{7}$ hence, equal doses $\left(0.12 \mathrm{mg} \cdot \mathrm{kg}^{-1}\right)$ of pancuronium and vecuronium were chosen. ${ }^{8}$ A $1: 4$ ratio $\left(0.4+1.6 \mathrm{mg} \cdot \mathrm{kg}^{-1}\right)$ was used in the pancuronium-metocurine mixture as described by Lebowitz et al. ${ }^{3}$

The contributions of preoperative medication and fentanyl to the observed haemodynamics cannot be distinguished from the cardiovascular effects of the neuromuscular blocker alone, as the latter was given during induction with fentanyl. However, since patient selection, preoperative medications, background anaes- 
thesia (fentanyl dose), and times of measurement were standardized, and since the four study groups were comparable regarding preoperative data and baseline haemodynamics, differences in observed haemodynamic responses following induction can be reasonably attributed to the different neuromuscular blockers used. Observations following intubation reflect the cardiovascular differences between the neuromuscular blocker-fentanyl groups when associated with the potent stimulation of laryngoscopy.

\section{Aortic stenosis}

Since coronary vascular reserve is limited in the presence of left ventricular hypertrophy, ${ }^{9}$ patients with severe aortic stenosis are more predisposed to myocardial ischaemia when $\mathrm{MVO}_{2}$ (myocardial oxygen demand) is increased or coronary blood flow (myocardial oxygen supply) is reduced. Tachycardia, which increases $\mathrm{MVO}_{2}$ and compromises coronary flow by reducing diastolic perfusion time, and hypotension that may further reduce coronary fluw, may be expected to cause myocardial ischaemia earlier in patients with aortic stenosis, and hence should be avoided during anaesthesia.

The most striking haemodynamic difference appeared in the HR responses in the fentanyl-pancuronium and the fentanyl pancuronium-metocurine mixture groups when comparcd to those who had received fentanyl-vecuronium or fentanyl-atracurium. This may be due to the fact that pancuronium, unlike vecuronium or atracurium, has vagolytic effects on cardiac muscarinic receptors,${ }^{10}$ facilitates norepinephrine release, ${ }^{11}$ and blocks norepinephrine reuptake by sympathetic nerve terminals. ${ }^{12}$ In contrast to previous reports, ${ }^{1,3}$ pancuronium-metocurine mixtures did not attenuate HR responses when compared to pancuronium alone. The mean maximum heart rate in our study was 96 beats'min $^{-1}$ (26 per cent increase over baseline) with pancuronium, and 94 beats $\cdot \mathrm{min}^{-1}$ ( $22 \mathrm{per}$ cent increase over baseline) with pancuronium-metocurine, unassociated with dysrhythmias or ECG signs of ischaemia. In one patient given pancuronium, tachycardia did result in severe hypotension requiring treatment with propranolol and a vasopressor.

Atracurium bas been reported to have minimal haemodynamic effects in both healthy patients ${ }^{13}$ and those with coronary artery disease, ${ }^{14}$ although an occasional patient can unpredictably develop hypotension usually ascribed to histamine release. ${ }^{14}$ Reductions in SVR following atracurium in our study allowed mean arterial pressures to fall which were clinically well tolerated with one exception.

The greatest hacmodynamic stability to induction and intubation was shown in patients given vecuronium with high-dose fentanyl. This is consistent with previous reports of minimal cardiovascular effects with 0.28 $\mathrm{mg} \cdot \mathrm{kg}^{-1}$ vecuronium $\left(12 \times \mathrm{ED}_{90}\right)$ with halothane anaesthesia in patients with coronary artery disease ${ }^{15}$ and 0.3 $\mathrm{mg} \cdot \mathrm{kg}^{-1}$ vecuronium in healthy, anaesthetized patients. ${ }^{16}$

\section{Aortic insufficiency}

The magnitude of regurgitant blood flow through an incompetent aortic valve is principally determined by the diastolic pressure gradient between the aorta and left ventricle and the duration of diastole. ${ }^{17}$ Increasing the diastolic gradient would increase regurgitation and this should be avoided in the anaesthetized patient. Abridgment of diastole by increasing heart rate usually has little effect on the severity of regurgitation, since only the last part of diastole in which least regurgitant flow occurs would be eliminated. ${ }^{17,18}$

In our patients, pancuronium, vecuronium and the pancuronium-metocurine mixture were associated with minimal cardiovascular changes when given with highdose fentanyl, and these anaesthetic techniques were well tolerated with the single exception of tachycardia following vecuronium. It is not clear why an increase in heart rate was not observed in patients with aortic insufficiency when pancuronium or the pancuronium-metocurine mixture was utilized. It is possible that in the pancuronium group, the high baseline heart rate in patients with aortic insufficiency may have prevented a further significant increase in heart rate. However, in the pancuroniummetocurine group, the baseline heart rate was similar to that in the aortic stenosis group. The elevations in systemic and pulmonary arterial pressures after fentanylatracurium were also unexpected and remain unexplained. Raised systemic arterial pressure would have increased the diastolic pressure gradient between the aorta and left ventricle, and most likely worsened the magnitude of regurgitant blood flow, resulting in the observed significant elevations in pulmonary capillary wedge pressure. Although only few patients could be studied, this observation occurred in four of five patients. These elevations in arterial pressures also account for the different trends noted with fentanyl-atracurium in patients with aortic insufficiency when compared to those with aortic stenosis in whom blood pressures fell after atracurium.

In summary, we showed that differences in cardiovascular responses occurred after induction with intubating doses of neuromuscular blockers in patients with aortic stenosis. Pancuronium and the pancuronium-metocurine mixture consistently allowed greater increases in heart rates, and reductions in blood pressure occurred with atracurium. Although these were not accompanied with 
ECG signs of ischaemia, one patient did develop severe hypotension from the tachycardia associated with pancuronium, suggesting that other neuromuscular blockers should be considered in preference to pancuronium in patients with critical left ventricular outflow obstruction. In contrast, pancuronium and the pancuronium-metocurine mixture permitted stable haemodynamics in aortic insufficiency patients. Also, in the aortic insufficiency group, atracurium caused unexplained elevations in systemic arterial pressure with possible increases in the aortic regurgitant blood fraction. Vecuronium, which does not release histamine or show autonomic effects, was generally associated with the most stable haemodynamic course in our patients.

\section{Acknowledgements}

We thank Kathy Roje for invaluable technical assistance, Jennifer Gassman for aid in statistical analysis, Jean Perkins for secretarial help, and our cardiac surgeons for their cooperation and agreement to study their patients.

\section{References}

1 Thomsan IR. Putnins CL. Adverse cffects of pancuronium during high-dose fentanyl anesthesia for coronary artery bypass grafting. Anesthesiology 1985; 62: 708-13.

2 Scott RPF. Savarese. $I J$. The cardiovascular and autonomic effects of neuromuscular blocking agents. Seminars in Anesthesia 1984; 3: 319-34.

3 Lebowitz PW, Ramsey FM, Savarese J, Ali HH, deBros $F M$. Combination of pancuronium and metocurine: neuromuscular and haemodynamic ad wantages over pancuronium alone. Anesth Analg 1981; 60: 12-7.

4 Miller RD, Rupp SM, Fisher DM et al. Clinical pharmacology of vecuronium and atracurium. Anesthcsiology 1984; 61: 444-53.

5 Miller $R G$ Jr. Simultuneous statistical inference. New York: Springer-Verlag, 1981.

6 Friedman LM, Furberg CD, DeMets DL. Fundamentals of clinical trials. Boston Massachusetts: John Wright, PSG Inc, 1983: p 167.

7 Gramstad L, Lilliaasen $P$. Dose-response relation for atracurium, $\mathrm{ORG} \mathrm{NC} 45$ and pancuronium. $\mathrm{Br} J$ Anacsth 1982: 54: 647-51.

8 Salmenpera $M$, Peltola $K$, Takkunen $O$, Heinonen J. Cardiovascular effects of pancuronium and vecuronium during high-dose fentanyl anesthesia. Anesth Analg 1983; 62: 1059-64.

9 Hoffman JIE. Maximal coronary flow and the cancept of coronary vascular reserve. Circulation 1984; 70: 153-9.
10 Saxena $P R$, Bonta $I L$. Mechanism of selective cardiac vagolytic action of pancuronium bromide. Specific blockade of cardiac muscarinic receptors. Eur J Pharmacol 1970; 11: $332-41$.

11 Bowman WC (Ed). The pharmacology of neuromuscular function. Bristol: John Wright and Sons Ltd, 1980: p 105.

12 Ivankovich $A D$, Miletich DJ, Albrecht RF, Zahed B. The effect of pancuronium on myocardial contraction and catecholamine metabolism. J Pharm Pharmacol 1975; 27 : 837-41.

13 Payne JP, Hughes $R$. Evaluation of atracurium in anaesthetized man. Br J Anaesth 1981; 53: 45.

14 Philbin DM, Machaj VR, Tomichek RC et al. Haemodynamic effects of bolus injections of atracurium in patients with coronary artery disease. Br J Anaesth 1983; 55 (Suppl 1): 131S-134S.

15 Morris RB, Cahalan MK, Miller RD, Wilkinson $P L, Q$ uasha $A L, R o b i n s o n S L$. The cardiovascular effects of vecuronium (ORG NC45) and pancuronium in patients undergoing coronary artery bypass grafting. Anesthesiology 1983; 58: $438-40$.

16 Lienhart A, Guggiari M, Tauvent A, et al. Effets hemodynamiques du vecuronium chez l'homme. Ann Fr Anesth Reanim 1983; 2: 7-16.

17 Brawley RK, Morrow AG. Direct determinations of aortic blood flow in patients with aortic regurgitation. Circulation 1967; 35: 32-45.

18 Wiggers $\mathrm{CJ}$. Modern concepts of hemodynamic effects of aortic insufficiency. W Virginia Med J 1960; 56: 327. 
Résumé

Afin de comparer les réponses hêmodynamiques assaciées à des doses équipotentes de bloqueurs neuromusculaires et une à dose élevée de fentanvl $\left(50 \mu \mathrm{g} \cdot \mathrm{kg}^{-1}\right)$, 40 patients avant une sténose de la valve aorique (SA) et 20 patients souffrant d'insuffisance aortique (IA) ont été répartis, de façon aléatoire, en quatre groupes d'ésude, afin de recevoir: (1) $0.12 \mathrm{mg} \cdot \mathrm{kg}^{-i}$ de pancuronium, (2) $0.12 \mathrm{mg} \cdot \mathrm{kg}^{-1}$ de vecuronium, (3) $0.4 \mathrm{mg} \cdot \mathrm{kg}^{-1}$ d'atracurium, on (4) une mixture de pancuronium-métocurine $(0.4 \mathrm{mg}+1.6 \mathrm{mg} / \mathrm{ml}): 1 \mathrm{mi} / 10 \mathrm{~kg}$. On injectait simulanément $\mathrm{le}$ fentanyl at bloqueurs neuromusculaires; les données hémodynamiques éraient enregistrées alors que les patients átaient éveillés (valeur témoin) à deux minutes post indurtion, et d̀ deux et cinq minutes post intubaion.

Chez les patients ayant une $S A$, laugmentation de la frëquence cardaque était plus grande avec le pancuronium qu'avec le vécuromium ou l'atracurium; les fréquences cardiaques étaient aussi pius élevées avec la mixture de pancuronium-métocurine qu'avec le vécuronium. Quoiqu'à l'ECGiln'vavait pasde signe d'ischémie, il s'est produir une hypotension grave associée d̀ une kachycardie chez un patient avant reçu du pancuronium. Aprés l'injection d' atracurium, des réductions dans la RVS ont donné lieu d̀ des diminutions de PAM, petites mais significatives (p<0.01), qui étaient bien tolérées; cependant, il s'est produit the hypotension importante chez un patient. Dans le groupe recevan la mixture de pancuronium-métocurine, l'intubation a entraîné des augmentations significatives $(p<0.01)$ de la PAM. Le vécuronium a donné, dans l'ensemble, l'état hémodynamique le plus stable à tous les temps de mesure.

Par contre, des états hémodynamiques skables se sont manifestés après l' injection de vécuronium, de pancuronium et de mixture de pancuronium-métocurine, chez les patients souffrant de IA; un patient est devenu tachycarde à la suite de l' injection de vécuronium. L'atracurium a causé des élévations inexpliquées des pressions diastoliques et artérielles moyennes qui étaient significatives quand on les comparait d̀ celles produites avec le vécuronium $(p<0.01)$. Ces élévations ont entrainé des angmentations de la PCWP; les pressions PA moyennes et $P V C$ ont aussi augmenté. Il est nécessaire de faire une évaluation plus poussée de ces effets de l'atracurium chez les patients souffrant d'IA. 